\title{
Penerapan model REACT untuk meningkatkan keterampilan proses sains siswa pada materi arus listrik
}

\author{
S Sirajuddin ${ }^{1}$, Haris Rosdianto ${ }^{1}$, Emi Sulistri ${ }^{1}$ \\ ${ }^{1}$ Prodi Pendidikan Fisika, STKIP Singkawan, Kota Singkawang 79151, Indonesia \\ E-mail: siradjuddin92@gmail.com; harisrosdianto@yahoo.com; sulistriemi@gmail.com
}

Received: 0201 2018. Revised: 2901 2018. Accepted: 12022018

\begin{abstract}
Abstrak
Penelitian ini bertujuan untuk mengetahui peningkatan Keterampilan Proses Sains (KPS) siswa setelah diterapkan model pembelajaran REACT. Jenis Penelitian ini adalah penelitian kuantitatif dengan bentuk pre-eksperimen design dengan desain penelitian one group pre-test post-test design. Populasi dalam penelitian ini adalah semua siswa kelas XI dari salah satu SMKN di Kota Singkawang. Sampel dalam penelitian ini berjumlah 12 siswa dengan teknik pengambilan sampel berupa teknik purposive sampling. Peningkatan KPS diukur dengan menggunakan alat ukur tes berupa 8 soal pilihan ganda beralasan tentang KPS. Dari analisis dengan menggunakan $\mathrm{N}$-gain, diperoleh peningkatan KPS sebesar 0,37 dengan kategori sedang, karena terletak pada rentang indeks gain yaitu $0,3 \leq<\mathrm{g}><0,7$. Model REACT dapat dijadikan salah satu model pembelajaran fisika untuk meningkatkan keterampilan proses sains siswa khususnya pada materi arus listrik
\end{abstract}

Kata Kunci: model REACT; keterampilan proses sains; arus listrik

\section{The Implementation of REACT Model to Improve Students' Science Process Skills in Electric Current Subject Matter}

\begin{abstract}
This study aims to determine the improvement of students' Science Process Skills after REACT learning model was implemented. The type of this research is quantitative research with pre-experiment design with one group pre-test post-test design. The population in this study are all students of class XI from one of SMKN in Singkawang City. The sample in this study amounted to 12 students by using purposive sampling technique. The improvement of Science Process Skills was measured using a test instrument in the form of 8 multiple-choice questions. From the analysis by using $N$-gain, obtained that students' Science Process Skills was improved by 0.37 with medium category, because it's in the range of gain index $0,3 \leq<g><0$, 7 . The REACT model can be used as a model of physics learning to improve students' science process skills especially in electrical current matter.
\end{abstract}

Keywords: REACT model; sicence process skills; electric current

\section{PENDAHULUAN}

Fisika adalah ilmu pengetahuan yang menggambarkan usaha, temuan, wawasan dan kearifan yang bersifat kolektif dari manusia (Wartono, 2003). Fenomena yang tampak di alam sekitar menjadikan rasa ingin tahu siswa meningkat (Sulistri, 2013). Siswa harus aktif memecahkan masalah dalam kegiatan laboratorium melalui kegiatan pengamatan, merumuskan masalah, merencanakan penyelidikan, melakukan percobaan, menggunakan perangkat untuk mengumpulkan data, menemukan jawaban, dan melakukan prediksi serta mengkomunikasikan hasil yang diperoleh (Setiawan dkk, 2012).

Menemukan solusi di sebuah masalah dalam eksperimen bermula dengan melakukan kegiatan pengamatan (Rosdianto 
\& Toifur, 2017). Siswa melakukan pengamatan untuk mengetahui fenomena atau masalah yang terjadi dihadapan secara langsung, kemudian membuktikannya melalui uji coba (Sulistri, 2016). Dari hasil pengujian tersebut, maka didapatkan informasi yang digunakan untuk menemukan solusi atau memecahkan sebuah permasalahan (Rosdianto, 2017). Keterampilan dan sikap yang dimiliki para ilmuan untuk memperoleh, mengembangkan pengetahuan serta mengetahui dan memecahkan permasalahan sebuah fenomena disebut Keterampilan Proses Sains (KPS) (Siska dkk, 2013). KPS sangatlah penting untuk mengembangkan ilmu pendidikan serta kualitas belajar siswa baik itu teori maupun keterampilan dalam bereksperimen. Salah satu permasalahan yang terdapat dalam proses pembelajaran fisika saat ini adalah rendahnya kualitas pembelajaran (Kusuma dkk, 2015). Kualitas pembelajaran meliputi keterampilan-keterampilan siswa dalam menemukan sesuatu hal baru.

Dari hasil observasi yang dilakukan pada bulan September di salah satu SMKN Singkawang kelas XI, disimpulkan bahwa siswa memiliki keterampilan proses sains yang rendah. Adapun rekapitulasi hasil observasi, dapat dilihat pada Tabel 1.

Tabel 1. Rekapitulasi Hasil Observasi

\begin{tabular}{|c|c|}
\hline Kegiatan & Dampak pada Siswa \\
\hline $\begin{array}{r}\text { Pembelaj } \\
\text { berpusat } \\
\text { guru }\end{array}$ & $\begin{array}{l}\text { menimbulkan rasa jenuh, } \\
\text { tidak ada rasa ingin tahu } \\
\text { terhadap konsep materi } \\
\text { yang diberikan }\end{array}$ \\
\hline $\begin{array}{r}\text { Siswa ku } \\
\text { dilibatkan } \\
\text { prose } \\
\text { pembela }\end{array}$ & $\begin{array}{l}\text { Siswa jarang berdiskusi } \\
\text { untuk membahas sebuah } \\
\text { fenomena (masalah) }\end{array}$ \\
\hline $\begin{array}{c}\text { Proses } \\
\text { pembelajaran } \\
\text { tidak diselingi } \\
\text { dengan } \\
\text { merencanakan } \\
\text { dan melakukan } \\
\text { percobaan }\end{array}$ & $\begin{array}{lr}\text { cara berpikir siswa } \\
\text { dalam } & \text { ketidakpastian } \\
\text { terhadap hasil belajarnya }\end{array}$ \\
\hline $\begin{array}{l}\text { Tes keterar } \\
\text { proses sain }\end{array}$ & $\begin{array}{l}85 \% \text { dari siswa belum } \\
\text { mencapai standar } \\
\text { ketuntasan yang telah } \\
\text { ditentukan peneliti. }\end{array}$ \\
\hline
\end{tabular}

Mengingat KPS menjadi bagian penting dalam mengembangkan pengetahuan, maka perlu diterapkannya model pembelajaran yang membuat siswa memahami materi dengan tidak hanya membaca melainkan melakukan kegiatan upaya menemukan hal baru. Model pembelajaran fisika yang mampu membantu siswa tidak hanya sekedar memahami konsep tetapi juga menemukan konsep sendiri ialah model pembelajaran REACT (Relating, Experiencing, Appliying, Cooperating, dan Transfering). REACT merupakan salah satu model yang menerapkan pembelajaran konstektual (Sulistyaningsih dkk, 2015).
Pada tahap yang pertama Relating proses kegiatannya dimana guru menghubungkan konsep yang dipelajari dengan materi pengetahuan yang dimiliki siswa. Tahap yang kedua Experiencing diamana siswa melakukan kegiatan eksperimen dan guru memberikan penjelasan untuk mengarahkan siswa menemukan pengetahuan baru. Tahap ketiga Applying dimana siswa menerapkan pengetahuan yang dipelajari dalam kehidupan sehari-hari. Tahap keempat Cooperating diamana siswa melakukan diskusi kelompok untuk memecahkan permasalahan dan mengembangkan kemampuan berkolaborasi dengan teman dan 
tahap kelima Transfering dimana siswa menunjukkan kemampuan terhadap pengetahuan yang dipelajari dan menerapkannya dalam situasi dan konteks baru. Dari latar belakang di atas peneliti tertarik untuk meneliti, apakah KPS dapat meningkat setelah diterapkan model REACT.

\section{METODE}

Jenis penelitian ini ialah penelitian kuantitatif, dengan bentuk Pre-experimental. Design penelitian menggunakan one group pretest post-test design, dengan tidak menggunakan kelas sebagai pembanding, melainkan menggunakan tes awal, sehingga besar pengaruh dapat diketahui secara jelas. Populasi dalam penelitian ini adalah semua siswa kelas XI di salah satu SMKN di kota Singkawang dan sampelnya adalah salah satu dari empat belas kelas XI. Teknik pengambilan sampel dalam penelitian ini adalah purposive sampling. Dimana metode purposive sampling ialah penarikan sampel secara sengaja, karena telah diketahui sampel tersebut mempunyai potensi mampu dalam bereksperimen dan pantas untuk dijadikan sampel atau memenuhi persyaratan

Teknik pengumpulan data dalam penelitian ini menggunakan tes KPS. Tes yang berbentuk soal pilihan ganda berasalan sebanyak 8 soal. Instrumen yang digunakan adalah lembar prestest dan postest. Sebelum diujikan, instrumen telah diujicobakan untuk mengetahui tingkat kesukaran, daya pembeda dan reliabilitasnya. Hasil tes dianalisis dengan menggunakan rumus $\mathrm{N}$-gain

\section{HASIL DAN PEMBAHASAN}

Dari hasil penelitian yang dilakukan diperoleh peningkatan setiap aspek KPS dengan menggunakan $\mathrm{N}$-gain sebagai berikut:

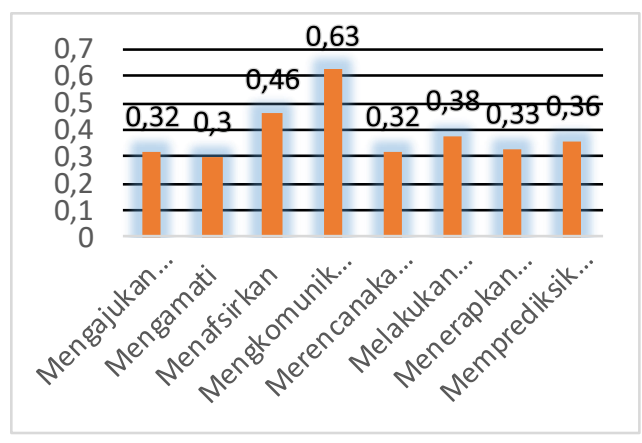

Gambar 1. Grafik Skor n-gain setiap aspek KPS

Dari data di atas dijelaskan bahwa aspek mengajukan hipotesis mengalami peningkatan sebesar 0,32 dengan kategori sedang. Aspek mengamati mengalami peningkatan sebesar 0,30 dengan kategori sedang. Aspek menafsirkan mengalami peningkatan sebesar 0,46 dengan kategori sedang. Aspek mengkomunikasikan mengalami peningkatan sebesar 0,63 dengan kategori sedang. Aspek merencanakan percobaan mengalami peningkatan sebesar 0,32 dengan kategori sedang. Aspek melakukan percobaan mengalami peningkatan sebesar 0,38 dengan kategori sedang. Aspek menerapkan konsep mengalami peningkatan sebesar 0,33 dengan kategori sedang dan aspek memprediksikan mengalami peningkatan sebesar 0,36 dengan kategori sedang. Dari keseluruhan aspek yang diteliti, rata-rata peningkatan seluruh aspek yang diteliti diperoleh sebesar 0,37 setelah diterapkannya pembelajaran REACT. Hal ini membuktikan bahwa pembelajaran REACT dapat membantu siswa dalam meningkatkan KPS.

Berdasarkan hasil analisis data dapat dilihat bahwa pada semua aspek KPS mengalami peningkatan setelah diterapkan model pembelajaran REACT. Aspek mengajukan hipotesis yang diterapkan pada tahap Relating mengalami peningkatan sebesar 0,32 dengan kategori sedang, peningkatan KPS pada aspek mengajukan hipotesis dikarenakan siswa mampu menjelaskan pengamatannya tentang simulasi arus listrik AC yang ditampilkan sebelum kegiatan eksperimen dimulai, hal ini diperkuat oleh pernyataan Semiawan bahwa 


\section{Jurnal Pendidikan Fisika dan Keilmuan (JPFK), 4 (1), 2018 - 22}

S Sirajudin, Haris Rosdianto, Emi Sulsitri

siswa mampu dalam memperkirakan hasil pengamatannya dengan alasan untuk menerangkan hasil pengamatan tersebut (Semiawan dkk, 1992). Aspek mengamati yang diterapkan pada tahap Relating mengalami peningkatan sebesar 0,30 dengan kategori sedang, peningkatan KPS pada aspek mengamati dikarenakan siswa teliti melakukan pengukuran dalam mengamati dengan menggunakan indra penglihatan serta membaca nilai-nilai pada objek yang diamati maupun simulasi arus listrik AC yang ditampilkan, hal ini diperkuat oleh penelitian Putra yang menyatakan bahwa penguasaan kosa kata dan bahasa yang baik dapat membuat siswa mampu melatih keterampilan proses sains seperti melakukan review (Putra dkk, 2005). Aspek menafsirkan yang diterapkan pada tahap Cooperating mengalami peningkatan sebesar 0,46 dengan kategori sedang, peningkatan KPS pada aspek menafsirkan dikarenakan siswa mampu mengumpulkan data hasil pengamatan dan pengukuran saat melakukaan kegiatan eksperimen seperti besar hambatan listrik dan tegangan listrik, hal ini diperkuat oleh pernyataan Semiawan bahwa siswa mampu dalam mengubah bentuk data seperti hasil observasi yang dilakukan saat eksperimen kemudian diuraikan dalam serangkai kalimat berupa kesimpulan eksperimen mereka (Semiawan dkk, 1992). Aspek mengkomunikasikan yang diterapkan pada tahap Transfering mengalami peningkatan sebesar 0,63 dengan kategori sedang. Peningkatan KPS pada aspek mengkomunikasikan paling tinggi dibandingkan dengan keterampilan lainnya. Hal ini konsisten dengan penelitian yang dilakukan oleh Chabalengula, V.M (2012) dan Aydogdu, B (2015) yang melaporkan bahwa peserta didik memiliki keterampilan mengkomunikasikan yang lebih baik dan paling tinggi dibandingkan keterampilan lainnya. Peningkatan dikarenakan siswa mampu dalam menyampaikan data seperti mempresentasikan hasil observasi mereka dalam eksperimen tentang arus listrik AC. hal ini diperkuat oleh penelitian Budiyono yang menyatakan bahwa siswa terlibat langsung dalam merancang dan mengkomunikasikan hasil percobaan dalam kegiatan praktikum yang dilakukan untuk menguji eksperimen yang telah dibuat (Budiyono dkk, 2016). Aspek merencanakan percobaan yang diterapkan pada tahap Experiencing mengalami peningkatan sebesar 0,32 dengan kategori sedang, peningkatan KPS pada aspek merencanakan percobaan dikarenakan siswa mampu menyusun tahap kegiatan percobaan arus listrik AC seperti mempersiapkan multitester, power supply dan bahan yang akan di uji cobakan, hal ini diperkuat oleh pernyataan Semiawan bahwa siswa mampu mempersiapkan alat serta bahan sebelum melakukan kegiatan uji coba untuk membuktikan gagasan-gagasan materi uji coba (Semiawan dkk, 1992). Aspek melakukan percobaan yang diterapkan pada tahap Experiencing dan Applying mengalami peningkatan sebesar 0,38 dengan kategori sedang, peningkatan KPS pada aspek melakukan percobaan dikarenakan siswa mampu melakukan kegiatan eksperimen tentang arus listrik AC serta mampu dalam mengoperasikan power suplly dan multitester dengan langkah-langkah yang benar sesuai dengan perencanaan sebelum melakukan eksperimen, hal ini diperkuat oleh pernyataan Semiawan bahwa siswa mampu menguji atau membuktikan sebuah gagasan dengan kegiatan uji coba tentang arus listrik AC (Semiawan dkk, 1992). Aspek menerapkan konsep yang diterapkan pada tahap Applying mengalami peningkatan sebesar 0,33 dengan kategori sedang, peningkatan KPS pada aspek menerapkan konsep dikarenakan siswa mampu menggunakan konsep yang telah dimiliki untuk menemukan jawaban atas pertanyaan atau masalah dalam ruang lingkup eksperimen serta menjawab pertanyaan (LKS) terkait konsep arus listrik AC yang diberikan, hal ini diperkuat oleh pernyataan Semiawan bahwa siswa mampu menggunakan konsep yang telah dimiliki untuk memecahkan masalah dalam eksperimen (Semiawan dkk, 1992). Aspek memprediksikan yang diterapkan pada tahap Cooperating mengalami peningkatan sebesar 0,36 dengan kategori sedang, peningkatan KPS pada aspek memprediksikan dikarenakan siswa mampu dalam memperkirakan sesuatu atau gejala tertentu berdasarkan hasil pengamatan serta penelitiannya sewaktu eksperimen tentang arus listrik AC. Hal ini diperkuat oleh penelitian Siska yang menyatakan bahwa saat pembelajaran siswa dilatih menemukan 
sendiri pola dan keteraturan dari data hasil percobaan (Siska dkk, 2013).

Berdasarkan hasil $\mathrm{N}$-gain, peningkatan KPS dikategorikan sedang karena siswa masih belum terbiasa melakukan pembelajaran dengan model REACT, hal ini dapat dilihat pada lembar respon siswa sebagian besar menyatakan bahwa pembelajaran yang dialaminya berbeda dengan pembelajaran sebelumnya.

\section{SIMPULAN}

Berdasarkan hasil dan pembahasan yang dilakukan, dapat disimpulkan bahwa penerapan model REACT dapat meningkatkan keterampilan proses sains siswa pada materi arus listrik sebesar 0,37 dengan kategori sedang. Model pembelajaran REACT sebaiknya diterapkan pada materi fisika yang memungkinkan siswa untuk melakukan praktikum. Selain itu, di awal pembelajaran siswa sebaiknya diberi motivasi agar semangat dan rasa ingin tahu mereka meningkat.

\section{DAFTAR PUSTAKA}

Aydogdu, B. (2015). The investigation of science process skills of sciencet Teachers in terms of some variables. Academic Journal Educational Research and Reviews, 10(5): 582594.

Budiyono, A., \& Hartini. (2016). Pengaruh Model Pembelajaran Inkuiri Terbimbing Terhadap Keterampilan Proses Sains Siswa SMA. Jurnal Pemikiran Penelitian Pendidikan Sains, 4(2).

Chabalengula, V. M., Mumba, F., \& Mbewe, S. (2012). How pre-service teachers' understand and perform science process skills. Eurasia Journal of Mathematics, Science \& Technology Education, 8(3), 167-176.

Kusuma, T.A., Indrawati, \& Harijanto, A. (2015). Model Discovery Learning Disertai Teknik Probing Prompting Dalam Pembelajaran Fisika Di MA. Jurnal Pendidikan Fisika, 3(4).

Putra, A.I.H., Widoretno, S., \& Prayitno, A.B. (2015). Peningkatan Keterampilan Proses Sains (KPS) Dasar Siswa Melalui Penerapan
Model Learning Cycle 5E Di Kelas VIII G SMP Negeri 22 Surakarta Tahun Pelajaran 2012/2013. Jurnal Pendidikan Biologi, 7(1), 89-100.

Rosdianto, H. (2017). Penentuan Percepatan Gravitasi Pada Percobaan Gerak Jatuh Bebas Dengan Memanfaatkan Rangkaian Relai. SPEKTRA: Jurnal Fisika dan Aplikasinya, 2(2), 107112.

Rosdianto, H., \& Toifur, M. (2017). Implementasi Teori Distribusi Probabilitas Gaussian Pada Kualitas Rangkaian Penyearah Gelombang Penuh. SPEKTRA: Jurnal Fisika dan Aplikasinya, 2(1), 83-90.

Semiawan, C., Tangyong, A.F., Belen, S., Matahelemual, Y., \& Suseloarjdo, W. (1992). Pendekatan Keterampilan Proses. Jakarta. Gramedia.

Setiawan, A., Sutarto, \& Indrawati. (2012). Metode Praktikum Dalam Pembelajaran Pengantar Fisika SMA: Studi Konsep Besaran Dan Satuan. Jurnal Pembelajaran Fisika, 1(3).

Siska, B.M., Kurnia, \& Sunarya, Y. (2013). Peningkatan Keterampilan Proses Sains Siswa SMA Melalui Pembelajaran Praktikum Berbasis Inkuiri Pada Materi Laju Reaksi. Jurnal Riset dan Praktik Pendidikan Kimia, 1(1).

Sulistri, E. (2013). Analisis Interferensi Cahaya Laser Terhambur Menggunakan Cermin Datar "Berdebu" Untuk Menentukan Indeks Bias Kaca. Jurnal Fisika, 3(1).

Sulistri, E. (2016). The Development of Activity Based Assessment (ABA) to Measure Students' Science Process Skill on the Basic Physics II Practicum Courses. Prosiding, International Conference on Teacher Education And Professional Development (INCoTEPD) 2016, 113-119.

Sulistyaningsih, D., \& Prihaswati, M. (2015). Pembelajaran Matematika Dengan 
Jurnal Pendidikan Fisika dan Keilmuan (JPFK), 4 (1), 2018 - 22

S Sirajudin, Haris Rosdianto, Emi Sulsitri

Model REACT Untuk Meningkatkan

Kemampuan Koneksi Matematik

Materi Dimensi Tiga Kelas X. Jurnal

Karya Pendidikan Matematika, 2(2).
Wartono. (2003). Strategi belajar mengajar fisika. Malang: Jurusan Pendidikan Fisika FMIPA Universitas Negeri Malang. 